\title{
A Post-Colonial Approach to The Man Who Ended History: A Documentary
}

\author{
Zhehui Zhang ${ }^{1}$ \\ ${ }^{1}$ School of Foreign Languages, Inner Mongolia University for Nationalities, China \\ Correspondence: Zhehui Zhang, School of Foreign Languages, Inner Mongolia University for Nationalities, 536 \\ Huolinhe Street West, Tongliao, Inner Mongolia Autonomous Region, China. E-mail: 18747555374@qq.com
}

Received: March 10, 2020 Accepted: April 12, 2020 Online Published: April 16, 2020

doi:10.5539/ells.v10n2p53 URL: https://doi.org/10.5539/ells.v10n2p53

\begin{abstract}
The Man Who Ended History: A Documentary is a science fiction by Chinese American science fiction writer Ken Liu (1976-). Based on the theory of Post-Colonial Criticism, this paper makes a concrete analysis of the text from the perspectives of three eminent contemporary theorists, aiming at the readers' better understanding of the work, and eliminating ethnocentrism, racism, unilateralism and hegemony; keeping history in mind and justifying the names of innocent humans who have been persecuted; safeguarding world peace, and building a community with a shared future for mankind.
\end{abstract}

Keywords: post-colonial criticism, secular critic and exiling intellectual, female, hybridity, a community with a shared future

\section{Introduction}

The protagonist, Chinese American historian Evan Wei, and his wife, Japanese American physicist Akemi Kirino, in order to restore the atrocities of Japanese Unit 731 to the world, together made a machine that can bring participants back to the past to witness historical events, but ended up with many disputes. Although the novel finally missed the Hugo Award due to its "political sensitivity", it is still Liu Yvkun's "proudest" work, it is still Liu Yvkun's "proudest" work. In the literature review of CNKI, using "The man who ended history: A Documentary" as the key words, title and theme respectively, there are two essays among which there is one cross existing, so there is only one research on The Man Who Ended History: A Documentary. The search results show that the research on The man who ended history: A Documentary is very limited. With "Liu Yukun" as the key word, there are 48 advanced search results; 47 search results with "Liu Yukun" in the title; 74 search results with "Liu Yukun" as the theme. Among them, there are 26 references overlapping among all the search terms, so there are only 48 studies on Liu Yukun, 44 of which are related to translation studies. It can be seen that there is less research on Liu Yukun's The man who ended history: A Documentary in China. Through Google academic search for foreign studies, the results are almost as the same. So, the call for further research is necessary. The main body of this thesis is divided into three parts: the first part is Edward Said's secular critic and exiling intellectual concept and their "voyage in" Europe and America discourse; the second part starts from the female concept in Spivak's post-colonial criticism to analyze the narrative of the heroine, Akemi Kirino; the third part is the hybridity concept of Homi K·Bhabha and its embodiment in the story. Through the research, there will be the revelation of why Liu Yvkun is called an excellent science fiction novelist, of why Liu Yvkun lost the award, and warning for the development of peace and the world's ethnic and cultural diversity.

\section{Edward Said's View on Secular Critic and Exiling Intellectual}

The intellectual is neither a pacifier nor a consensus-builder, but someone whose whole being is staked on a critical sense, a sense of being unwilling to accept easy formulas, or ready-made cliches, or the smooth, ever-so-accommodating confirmations of what the powerful or conventional have to say, and what they do (Said, 1994, p. 23). With the help of Said's intellectual theory, the author Ken Liu expresses the real connotation and significance of The man who ended history: A Documentary by shaping the intellectual images of Evan and Akemi Kirino, so as to arouse people's rational understanding of history and concern for a community of shared future for mankind. 


\subsection{Secular Intellectuals Typified by Dr. Wei and Dr. Kirino}

Chinese American historian Evan Wei, and his wife, Japanese American physicist Akemi Kirino, facing with their own multiple social identity and with the atrocities of Japanese Unit 731 to Chinese people, what choices will they make on the key decisions that will determine how the truth goes? Who will they speak for? Chinese? Japan? American? Or the truth? Together they made a machine that can bring participants back to the past to witness this real historic event. Said said "the intellectual is neither a pacifier nor a consensus-builder, but someone whose whole being is staked on a critical sense, a sense of being unwilling to accept easy formulas, or ready-made cliches, or the smooth, ever-so-accommodating confirmations of what the powerful or conventional have to say, and what they do" (Said, 1994, p. 23). This can be seen from "Dr. Wei has insisted that he and his wife are conducting this experiment in their capacities as individual American citizens, with no connection to any government... and protect their effort from any governmental interference" (Ken, p. 118) and "Akemi Kirino's reflection". The truth is not delicate and it does not suffer from denial- the truth only dies when true stories are untold; the silence of the victims of the past imposes a duty on the present to recover their voices, and we are most free when we willingly take up that duty (Ken, p. 164).

\subsection{Their Voyage in European and American Discourse}

The voyage in refers to the anti-imperialist intellectual and scholarly work done by writers from the peripheries who have immigrated to or are visiting the metropolis (Said, 1993, p. 244). Here's an interesting analogy, Chinese American historian Evan Wei, and his wife, Japanese American physicist Akemi Kirino are the anti-imperialist intellectuals, the Bohm-Kirino particle is the scholarly work, the author Ken Liu is the peripheries who have immigrated to the metropolis and the witness Lillian C. Chang-Wyeth is in the western world the so-called "the other". They restore the atrocities of Japanese Unit 731 to the world through the testimony of the volunteer Lillian C. Chang-Wyeth who were brought back by Bohm-Kirino particle. They are keen on conveying the thoughts from non-western to the west and voyage in European and American discourse by what Lillian C. Chang-Wyeth said: "What I really want is for what I saw never have happened...to have my aunt's story remembered, to have the guilt of her killers and torturers laid bare to the gaze of the world...I am sorry to say that the government of thee United States has also never acknowledged or apologized for its role in shielding these criminals from justice after the War..." (Ken, p. 141).

\section{Gayatri Chakravorty Spivak's View on Females}

Gayatri Chakravorty Spivak is a noted female theorist in post-colonialism, and she is also involved in feminism, psychoanalysis, deconstruction and Marxism. Facing with the situation that western feminists pay attention to white women, while male post-colonial theorists and nationalists pay attention to men in the third world, and the unique identity and situation of women in the third world are always out of the theoretical horizon (Luo \& Liu, 1999, p. 7), in terms of post-colonial theory, she compensates for a lack of theoretical perspective other than Said, Bhabha and others from feminism and also makes post-colonial research more complicated (Zhu, 2006, p. 483).

\subsection{Japanese American Dr. Kirino's Prominent Achievements in Scientific Research}

She believes that any attempt to describe and explain the composition of female gender subject with western central discourse and regard it as a universal theory is actually a kind of imperialist sophistication, even a kind of hegemonic feminism. Ignoring the heterogeneity and difference of the third world, the practice of blindly instilling white feminism into it is not a real universal feminism, but a kind of gender theory colonization (Guan, 2017, pp. 188-189). In addition to other people's deep-rooted prejudice and sexual fantasy towards Japanese women, Akemi Kirino described herself: "It didn't help that I knew my way around power tools better than most of them - a necessary skill for a lab physicist" (Ken, pp. 123-124). In the eyes of outsiders, she should be a timid and lovable little woman, obsessed with animation, not a chief scientist in laboratory. Nevertheless, the author endows her - a female, an Asian American woman - with good looks and rich knowledge, which greatly inspires the third world women, and also enables the third world women to enter the public vision dominated by men and white women.

\subsection{Japanese American Dr. Kirino's True Self Guaranteed in Her Marriage}

In many Third World countries, there are indeed some different customs, especially some social rules and requirements for women, which seem to be unacceptable to outsiders. Therefore, some people take this as a reason to uphold "justice". These people just ignore the differences of the women from the first world and from the third world, and pattern Western standards as universal values. Fu Lei's 2019 study (cited in Spivak, 1987) found that knowledge can be produced and maintained by the difference of irreducible contract rather than the identity (Spivak, 1987, p. 254). If there is such understanding and tolerance, then culture will coexist 
harmoniously. In Liu's story, Akemi Kirino's words can be the evidence that she, as a successful female intellectual of Asian descent, has been protected and respected in her marriage." Some of my old boyfriends used to tell me that my focus on the quantifiable and the logic of mathematics made me seem cold and unfeminine. Evan was the only man I knew who was perfectly happy to defer to me when I told him that I could do something requiring mechanical skills better than he could" (Ken, pp. 123-124). For her husband Evan unlike other people, does not hold the view that Japanese women are full-time housewives, tender and soft, and abandon their careers completely. Evan accepts her focus on the quantifiable and the logic of mathematics, and her efforts to pursue her own value.

\section{Homi K·Bhabha's View on Cultures}

In The man who ended history: A Documentary, the personal identity and the more complex network of marriage relationship of the protagonists, Evan Wei and Akemi Kirino, are intentionally created by the author. This kind of collision is what Bhabha believes Hybridity is a problem of colonial representation and individuation that reverses the effects of the colonialist disavowal, so that other 'denied' knowledge enter upon the dominant discourse and estrange the basis of its authority - its rules of recognition (Bhabha, 1994, p. 113), which is conducive to melting the ice of national hostility and providing possibility for cultural support and reconciliation.

\subsection{The Hybridity in Mr. and Mrs. Wei's Individual Identity}

"Hybridity takes the colonized culture away from his or her own culture and identity, shaping the people who are neither themselves nor their colonizers. So, in other words, there are people who are sort of in-between without identity" (Wang, 2019, p. 6). In fact, it's not hard to understand that Evan Wei is Chinese American, and Akemi Kirino is Japanese American, in Akemi Kirino's word: "We had both come to America as young children, and knew something about the meaning of growing up as outsiders trying hard to become Americans." Although they are Chinese, Japanese or Americans in terms of their physical characteristics, ways of thinking, language behaviors, etc., they are actually not complete Chinese, Japanese or Americans as the whole. This mixture of identities enables them to get rid of extremism and have a cultural vision beyond a single nation. Evan said that Akemi Kirino's name "allowed him to picture it in those old characters that are the common heritage of China and Japan, and thus keeping in mind their meaning" (Ken, p. 123). Not conforming to the usual stereotype of Japanese girl as "interested in anime, love karaoke, and giggle into...Oriental sex fantasies" (Ken, p. 124), Akemi Kirino felt tired. However, as Akemi Kirino said "Evan made me proud to be Japanese, and so he made me love myself" (Ken, p. 125).

\subsection{The Hybridity in Mr. and Mrs. Wei's Marital Relationship}

The marriage between Evan and Akemi Kirino is a mixture of identity and culture. The combination of the two has brought the discourse environment into a broader space. In this culture magnetic field, there are three invisible gravitation interacting in the three-dimensional space. This is actually metaphorically referred to the response and thinking mode of China, Japan and America to the atrocities committed by the Unit 731. There are several records of the interviewees' comments that come from all walks of life in China, Japan, America and Australia and that can be concluded as the three kinds: being indifferent; supporting for the revelation of the violence and historical facts to the public to comfort the dead and warn the public; refusing to recognize history and trying to erase it. Post-colonial itself is not a critical discourse against imperialism or colonialism. The purpose of post-colonial criticism is to weaken the Western cultural hegemony over the East and the third world countries (Sheng, 2011, p. 3). In the three-dimensional space of their marriage where three invisible gravitation of Chinese, Japan and American interact, Evan Chinese American and Akemi Kirino Japanese American, who have dual identities, do not stand for any country, but on the right side. Whether they are Chinese, Japanese, Americans or people in other countries in the world, they speak for the persecuted people and eliminate the cultural hegemony on the victims. This multicultural interaction makes communication and reconciliation possible and helps to build a community of shared future for mankind.

\section{Conclusion}

It is generally believed that the British Industrial Revolution and Darwin's theory of evolution led to the rise of real science fiction, while Einstein's theory of relativity in the early 20th century brought the rise of science fiction. Despite the controversy, Frankenstein, published by Mary Shelley in 1818, has been recognized by many as the first science fiction in the world. After more than two centuries of development, science fiction has developed into different types and gained more and more attention from all walks of life. Liu Yvkun brought the science fiction The man who ended history: A Documentary into the public view because of his unique identity, excellent writing ability, concern for human beings and backward view of reality. Through the method of post-colonial criticism, this paper analyzes the text from the perspectives of three notable theorists in order to 
enrich the academic research. It can be seen that the protagonists, Chinese American historian Evan Wei, and his wife, Japanese American physicist Akemi Kirino, are secular intellectuals as said by Said. They open the historical gate through the Bohm-Kirino particle to return to the past, voyage in the European and American discourse, and expose the crimes of imperialism and hegemonism. In the story, the description of female protagonist Akemi Kirino, compared with that of the Japanese militarism and the Bohm-Kirino particle experiment is relatively less, but she is endowed with an independent and complete female personality; then it comes to the identity of both Chinese Americans and Japanese Americans, which is a mixture as individual identity, and their marriage relationship creates a "trio", which makes cultural communication possible, so it is with the elimination of ethnocentrism, racism, unilateralism and hegemonism, which is conducive to safeguarding world peace and building a community of shared future for mankind.

\section{References}

Bhabha. H. K. (1994). The Location of Culture (p. 113). New York: Routledge.

Fu, L. (2019). A Study of Celeste Ng's Writing from the Perspective of Post-Colonialism (p. 13). JiMei University.

Guan, R. Z. (2017). A Study of G. C. Spivak's Theory (pp. 188-189). Shanghai: Fudan University Press.

Ken, L. (2019). The man who ended history: A Documentary. Retrieved December 15, 2019, from https://max.book118.com/html/2019/0129/8117023065002004.shtm

Luo, G., \& Liu, X. Y. (1999). Post-colonial Cultural Theory (p. 7). Beijing: China social sciences press.

Said, E. (1993). Culture and Imperialism (p. 244). New York: Alfred \& Knopf.

Said, E. (1994). Representations of the Intellectual: The Reith Lectures. New York: Pantheon Books.

Sheng, A. F. (2011). A Study of Homi K. Bhabha's Postcolonial Theories (p. 3). Beijing: Peking University Press.

Spivak, G. C. (1987). In Other Worlds: Essays in Cultural Politics (p. 254). New York: Methuen.

Wang, Q. (2019). Anxiefy, Resistance and Redemption: A Postcolonial Interpretation of Wide Sargasso (p. 6). Beijing University of Posts and Telecommunications.

Zhu, G. (2006). Twentieth Century Western Critical Theories (p. 483). Beijing: Peking University Press.

\section{Copyrights}

Copyright for this article is retained by the author, with first publication rights granted to the journal.

This is an open-access article distributed under the terms and conditions of the Creative Commons Attribution license (http://creativecommons.org/licenses/by/4.0/). 